\title{
Enjoyment during Exercise Mediates the Effects of an Intervention on Exercise Adherence
}

\author{
Darko Jekauc \\ Institute for Sport Science, Humboldt University of Berlin, Berlin, Germany \\ Email: darko.jekauc@hu-berlin.de
}

Received 26 December 2014; accepted 6 January 2015; published 16 January 2015

Copyright (C) 2015 by author and Scientific Research Publishing Inc. This work is licensed under the Creative Commons Attribution International License (CC BY). http://creativecommons.org/licenses/by/4.0/

(c) (i) Open Access

\section{Abstract}

Regular participation in physical activity is associated with a variety of health benefits and a reduction in diverse chronic diseases. However, empirical studies have shown that about $50 \%$ of the participants in exercise programs drop out during the first six months. One strategy to increase regular physical activity would be to promote positive feelings during exercise. The purposes of this experimental study were a) to investigate whether the affective states can be influenced by specific interventions and b) to link these changes in affective states to exercise adherence. The trainers of the experimental group were instructed to promote positive emotions (e.g. pleasure and fun) during exercise according to specific principles. The trainers of the control group were instructed to comply with the recommendations of the American College of Sports Medicine. 24 participants in the experimental group and 17 participants in the control group were recruited for this study. The results of the repeated measures analyses of variance provide a significant time by group interaction suggesting that participants of the intervention group increased their affective ratings significantly compared to the control group. The results of the hierarchical regression analyses support the hypothesis that the changes in affective ratings related to exercise mediated the effects of intervention on physical activity adherence. This study provides evidence that affective states during exercise can be systematically influenced to increase physical activity adherence. Principles on how to increase positive affective judgments related to exercising can be drawn from this study and eventually be used in order to promote regular physical activity among a large part of the population.

\section{Keywords}

Adherence, Affective States, Physical Activity, Enjoyment 


\section{Introduction}

Participation in physical activity is associated with a variety of health benefits and a reduction in diverse chronic diseases such as diabetes, cancer or cardiovascular diseases (Reiner et al., 2013). However, large parts of populations are not sufficiently physically active (Tucker et al., 2011). Several strategies have been proposed in order to increase or maintain levels of health enhancing physical activity among populations (Biddle, Brehm, Verheijden et al., 2012). However, the benefits of physical activity are only sustained with continuous and regular participation while stopping or substantially reducing physical activity can lead to a loss of the initially gained health improvement (Mujika \& Padilla, 2000). Empirical studies have shown that about 50\% of the participants in exercise programs drop out during the first six months (Annesi, 2003). Therefore, physical activity maintenance is an important aspect of health promotion.

However, empirical evidence suggests that in the process of physical activity maintenance different influencing factors are relevant than in the process of initiation of physical activity (Biddle \& Mutrie, 2008). Although important progress has been made in understanding the motivation to initiate participation in physical activity, relatively little research has specifically examined the maintenance of physical activity behavior (McAuley et al., 2007). In order to design effective interventions, it was recommended that a profound understanding of determinants of physical activity maintenance, drawing on a theoretical foundation, is needed (Baranowski et al., 1998).

Some theoretical positions, such as affect heuristic (Slovic et al., 2007), affect as information hypothesis (Schwarz \&Clore, 1983) or risk as feelings hypothesis (Loewenstein et al., 2001), propose that affective states might influence decision making and maintenance of behavior. According to Cacioppo and Berntson (1999), humans possess an affect system with a basic action tendency to approach pleasurable events and to avoid aversive ones. Consistently, Kahneman, Fredrickson, Schreiber, and Redelmeier (1993) could show that affective responses to a behavior may influence a decision regarding whether or not to repeat the behavior in question. Behavior associated with positive affects has a higher probability of being repeated than behaviors without such an association. On the contrary, an association with negative affects tends to decrease the probability of repeating the behavior. Thus, affective response to a behavior or situation can be an important aspect in the process of behavior maintenance (McAuley et al., 2007).

Meta-analysis conducted by Rhodes, Fiala, and Conner (2009) provided evidence that a medium effect size relationship between affective judgments and physical activity exists. However, most studies used in this metaanalysis are cross-sectional and do not contain any information on the relationship between affective judgments and adherence. Furthermore, 19 out of 20 experimental studies failed to change affective judgment-mainly because they implemented persuasion-based or self-regulatory techniques and did not explicitly focus on influencing affective states. For example, in one experimental study, the intervention did not significantly influence physical activity enjoyment but enjoyment at the end of the intervention significantly predicted physical activity at the follow up (Castro et al., 1999). Consequently, there is substantial evidence that affective variables are predictive of future physical activity but it is still unknown how affective variables can be influenced in order to increase physical activity adherence. Up to date, there is only insufficient evidence that affective variables can effectively be manipulated by physical activity interventions.

However, theoretical considerations on how affective states can be influenced have been made. In the selfdetermination theory for example, Deci and Ryan (2010) propose that humans have three psychological needs which intrinsically motivate the self to exert and to adhere to behavior: relatedness, competence and autonomy. It is supposed that the promotion of these three needs during exercise can also influence affective judgments related to behavior (Schneider \& Kwan, 2013). For example, providing positive feedback can increase self-perceived competence and enhance positive feelings during exercise. Furthermore, self-selected exercise intensity was also shown to be related to affective judgments (Ekkekakis et al., 2008; Williams \& Raynor, 2013). In practice however, these theoretical propositions were never been systematically tested - therefore it cannot be said if and to which extent affective judgments increase adherence to a behavior. The purposes of this study were a) to investigate whether the affective states can be influenced by specific interventions and b) to link these changes in affective states to exercise adherence.

\section{Methods}

\subsection{Participants}

45 adult participants were recruited from a health insurance company for participation in a course "fit mix". The 
course was free of charge for participants. 41 of the 45 participants committed themselves to take part in the study and agreed to be contacted for data collection. Participants freely opted for one of four courses of which two were assigned to the control group and two to the experimental group. In total, 15 women and 2 men were in the control group and 21 women and 3 men in the experimental group. The average age in the experimental group was 40.5 years and in the control group 54.1 years.

\subsection{Procedure}

In total, four exercise groups were offered. For each exercise group a trainer was recruited. Two trainers were randomly assigned to the experimental group and two to the control group. Prior to the beginning of the course, the trainers of the experimental group were instructed in a session to focus on enjoyment during the training. Derived from the self-determination theory (Ryan \& Deci, 2000), dual-mode theory (Ekkekakis, 2009) and a qualitative pre-study, six issues were presented to increase positive affect: 1) emphasizing group exercises instead of single exercises; 2) incorporating the participants into the process of decision-making when choosing the exercises; 3) providing a sense of achievement through positive feedback; 4) regulation of the intensity according to the abilities and wishes of the participants; 5) increasing the transparency of the training by pre-announcing the contents of the future training sessions; and 6) increasing the diversity of the training. In contrast, the trainers of the control group were instructed to increase the health benefits by using the training principles of the American College of Sports Medicine (Garber et al., 2011): 1) cardiorespiratory exercise; 2) resistance exercise; 3) flexibility exercise; and 4) neuromotor exercise. Additionally, the trainers of both groups were supplied by pamphlets to remind them of the instructed training principles. However, the trainers of both groups freely chose the exercises of the training.

The duration of all courses was eight weeks. Affective states were measured prior to the first session, at the end of the fourth session, and the end of the last session. In case that a participant could not make it to one measurement occasion, the questionnaire was filled in during the consecutive session or, alternatively, a student assistant dropped by at the participant's home in order to get the questionnaire filled in. Each session, the data was collected by a student assistant.

\subsection{Measurement}

\subsubsection{Adherence}

Adherence was measured by the attendance lists for each session.

\subsubsection{Affective States}

Affective states were measured by the German version of the Physical Activity Enjoyment Scale (PACES; Jekauc et al., 2013). The questionnaire consists of 18 statements ranging on a scale between two bipolar adjectives (e.g., enjoy-hate, bored-interested, pleasant-unpleasant) with seven response categories. The Cronbach's alpha was 0.79 .

\subsection{Statistical Analyses}

T-tests for independent samples were used to test the main differences at each measurement occasion. If the variances between the both groups differed significantly, Welch's t-test was used. To examine the influence of the experimental condition on the development of affective states, analyses of variance (ANOVA) with repeated measures were used. Because the assumption of sphericity for the ANOVA with repeated measurements was violated, the Greenhouse-Geisser correction was conducted. To examine the mediation effects of affective states in the relationship between experimental condition and adherence multiple hierarchical regression analyses were conducted. Because the experimental and control group significantly differed regarding the age of the participants all calculations were conducted using the variable age as a covariate and as an additional predictor.

\section{Results}

\subsection{Development of Affective States}

Table 1 presents means and standard deviations of the PACES and exercise frequency as well as t-tests for in- 
dependent samples. In the first session, the mean differences between the intervention and the control group in PACES were not significant. For the fourth and eighth session, the means of the intervention group in PACES were significantly higher than the means of the control group. The mean exercise frequency over eight weeks was significantly higher in the intervention group $(M=7.9)$ than in the control group $(M=7.2)$.

Table 2 provides the results of the ANOVA with repeated measures. The results show a significant interaction between time and group indicating that the intervention and the control group differ significantly in their development over time. The means of the intervention group increased constantly from the first $(M=68.9)$ to the fourth session $(M=71.1)$ whereas the means of the control group decreased from the first $(M=70.2)$ to the fourth session $(M=66.2)$. The effect size with an eta-square of $0.23(d=1.1)$ is large. Age did not significantly influence the development of the PACES.

\subsection{Prediction of Exercise Adherence}

The results of the hierarchical regression analysis in Table 3 show that group membership and age independently of each other influenced the adherence. The amount of explained variance was relative high with $49 \%$. However, when the PACES measures of the all three measurement occasions were included in the regression analysis the effects of the group membership were no longer significant suggesting that the intervention effects were mediated by the enjoyment related to exercise. The effects of age were not affected by the inclusion of PACES measures into the regression analysis.

\section{Discussion}

Physical inactivity is a huge public health concern. Providing new strategies to promote regular physical activity is an important aspect of public health research. There is sound empirical evidence that positive affective states can increase physical activity levels (Rhodes et al., 2009). However, little is known about how affective states

Table 1. Means and standard deviations for PACES and exercise frequency.

\begin{tabular}{ccccccc}
\hline & & $M$ & $S D$ & $t$ & $d f$ & $p$ \\
\hline $\begin{array}{c}\text { 1. Session } \\
\text { PACES }\end{array}$ & IG & 68.9 & 4.8 & -0.9 & 39 & 0.37 \\
& CG & 70.2 & 4.5 & & & \\
4. Session & IG & 71.1 & 1.9 & & & $<0.01$ \\
PACES & CG & 66.2 & 2.6 & 6.9 & 39 & \\
8. Session & IG & 71.3 & 1.8 & & & \\
PACES & CG & 65.8 & 3.0 & 6.7 & 24.0 & \\
Exercise & IG & 7.9 & 0.3 & & & 0.01 \\
Frequency & CG & 7.2 & 1.3 & 2.6 & 17.0 & 0.02 \\
\hline
\end{tabular}

Note: $M=$ Mean; $S D=$ standard deviation; $t=$ value of the t-distribution; $d f=$ degrees of freedom; $p=$ probability value; PACES = Physical Activity Enjoyment Scale; IG = intervention group; CG = control group.

Table 2. ANOVA with repeated measures for the PACES as dependent variable.

\begin{tabular}{ccccccc}
\hline & $S S$ & $d f$ & $M S S$ & $F$ & $p$ & $\eta^{2}$ \\
\hline Time & 2.0 & 1.1 & 1.7 & 0.1 & 0.76 & 0.00 \\
Time $\times$ Age & 8.0 & 1.1 & 7.0 & 0.5 & 0.51 & 0.01 \\
Time $\times$ Group & 189.6 & 1.1 & 166.0 & 11.6 & $<0.01$ & 0.23 \\
Error & 628.6 & 44.5 & 14.1 & & & \\
\hline
\end{tabular}

Note: $S S=$ sum of squares; $d f=$ degrees of freedom; $M S S$ = mean sum of squares; $F$ = value of the F-distribution; $p=$ probability value; $\eta^{2}=$ amount of explained variance in dependent variable; PACES = Physical Activity Enjoyment Scale; ANOVA = analysis of variance. 
Table 3. Hierarchical regression analysis to predict the adherence.

\begin{tabular}{ccccccc}
\hline & & $B$ & $S E$ & $\beta$ & $t$ & $p$ \\
\hline Step 1 & Intercept & 6.29 & 0.37 & & 16.9 & $<0.01$ \\
& Group & -1.40 & 0.25 & -0.72 & -5.5 & $<0.01$ \\
& Age & 0.04 & 0.01 & 0.61 & 4.7 & $<0.01$ \\
\hline \multirow{2}{*}{ Step 2 } & Intercept & 0.65 & 3.77 & & 0.17 & 0.85 \\
& Group & -0.40 & 0.45 & -0.21 & -0.89 & 0.38 \\
& Age & 0.04 & 0.01 & 0.61 & 4.7 & $<0.01$ \\
& PACES t1 & 0.01 & 0.03 & 0.10 & 0.08 & 0.94 \\
& PACES t2 & -0.63 & 0.09 & -0.21 & -0.74 & 0.47 \\
& PACES t3 & 0.14 & 0.08 & 0.52 & 1.82 & 0.08 \\
\hline & & $R^{2}=0.551 ; \Delta R^{2}=0.059 ; \Delta F_{3.35}=1.5 ; p=0.224$ & & \\
\hline
\end{tabular}

Note: $B=$ unstandardized regression coefficient; $S E=$ standard error; $\beta=$ standardized regression coefficient; $t=$ value of the t-distribution; $p=$ probability value; $R^{2}=$ total amount of explained variance; $\Delta R^{2}=$ difference in $R^{2}$ between step 1 and step 2; $\Delta F=$ difference in the F-value between step 1 and step 2; PACES = Physical Activity Enjoyment Scale.

can be systematically influenced to increase regular physical activity.

The first aim of this study was to examine whether the affective states can be influenced by specific interventions. The study provides the evidence that such a manipulation of affective states related to physical activity is possible. During the course of the exercise program the affective ratings of the participants in the intervention group increased whereas the affective ratings in the control groups decreased. The interaction between the factors "time" and "group" was significant indicating a strong effect $(\mathrm{d}=1.1)$. Therefore, it can be supposed that the measures applied to increase positive feelings during exercise were effective. The applied measures in the exercise course were 1) stressing the sense of relatedness among the participants of the exercise; 2) co-determination of the participants when choosing the exercises; 3 ) increasing the sense of achievement by providing positive feedback; 4) regulation of the intensity according to the abilities and the wishes of the participants; 5) providing the transparency of the training by pre-announcing the contents of the future training sessions; and 6) increasing the diversity of the training. It can be assumed that the instructions of the trainers to implement these principles in their training lead to more positive affective evaluations of the training sessions made by the participants. Stressing the principles of health-related training during the training sessions provoked contrary reactions, namely the feeling of boredom and satiation. This explains why the affective evaluations of the control group became more negative in the course of the training exercise. Furthermore, the results show that age could not significantly predict the development affective judgments.

The second aim of this study was to examine whether affective judgments during the training influenced exercise adherence. The difference between the intervention and the control group regarding exercise adherence was significant. Participants of the intervention group attended the exercise program more regularly compared to the control group. However, when the affective judgments were also taken into account in the regression analysis, the difference between the intervention and the control group was not significant any more. These results indicate that the affective judgments during the training mediated the effects of the intervention. Therefore, it can be supposed that changes in affective judgments during the training were responsible for the difference in adherence. Probably, the intervention group's participants as compared to the control group participants felt more comfortable during the exercise course and therefore experienced less difficulty in maintaining their motivation to exercise regularly. In comparison to that, the participants of the control group presumably suffered more from boredom and therefore faced greater difficulties motivating themselves to work out regularly. Furthermore, the results of this study suggest that age was a significant predictor exercise adherence. The effects of age on adherence are independent of physical activity enjoyment and the intervention. These results are consistent with 
finding of several empirical studies showing that age is an important determinant of physical activity (Trost et al., 2002).

This study provides a new and highly effective approach to influence feelings and affective judgments related to exercise. The above-mentioned strategies can be used to educate trainers and physical education teachers to implement these strategies in their courses. However, it is still unknown which of the above-mentioned measures really influenced affective judgments. Up until now, we only know that the sum of these strategies is highly effective in positively influencing affective judgments. Consequently, further studies need to be conducted in order to find out which of these measures really is effective and how one could possibly refine those measures. In this way, effective instructions and education strategies for trainers can be developed. This study provides the evidence that affective variables are important determinants of human behavior. Experiencing more positive feelings during a training session provides higher adherence to the training program. One possible strategy to increase physical activity levels could be to promote fun and pleasure during the training.

Nonetheless, this study has several limitations. First, the sample size of 41 participants is relatively small. However, this sample size is still large enough to reject the null hypothesis. But, further studies need to be conducted in order to approve these findings. Second, the period during which adherence has been examined may be short. However, these eight weeks are still long enough to show the mediation effects. Third, the variance in the variable adherence was relatively small as most participants attended the course regularly. Possibly, the effects would be even larger if the variance in adherence were larger. Nonetheless, to our knowledge, this is the first experimental study to examine the strategies for influencing affective states during physical activity to increase the adherence systematically.

\section{Conclusion}

The results of this study provide the first evidence that affective judgments related to physical activity can be systematically manipulated. The affective judgments were shown to influence physical activity adherence. Actors in the public health can apply the strategies in educating the trainers in order to increase levels and adherence of physical activity. However, further studies are needed in order to approve these findings.

\section{References}

Annesi, J. J. (2003). Effects of a Cognitive Behavioral Treatment Package on Exercise Attendance and Drop out in Fitness Centers. European Journal of Sport Science, 3, 1-16. http://dx.doi.org/10.1080/17461390300073206

Baranowski, T., Anderson, C., \& Carmack, C. (1998). Mediating Variable Framework in Physical Activity Interventions: How Are We Doing? How Might We Do Better? American Journal of Preventive Medicine, 15, 266-297. http://dx.doi.org/10.1016/S0749-3797(98)00080-4

Biddle, S. J. H., Brehm, W., Verheijden, M., \& Hopman-Rock, M. (2012). Population Physical Activity Behaviour Change: A Review for the European College of Sport Science. European Journal of Sport Science, 12, 367-383. http://dx.doi.org/10.1080/17461391.2011.635700

Biddle, S. J. H., \& Mutrie, N. (2008). Psychology of Physical Activity: Determinants, Well-Being and Interventions. Oxon: Routledge.

Cacioppo, J. T., \& Berntson, G. G. (1999). The Affect System Architecture and Operating Characteristics. Current Directions in Psychological Science, 8, 133-137. http://dx.doi.org/10.1111/1467-8721.00031

Castro, C. M., Sallis, J. F., Hickmann, S. A., Lee, R. E., \& Chen, A. H. (1999). A Prospective Study of Psychosocial Correlates of Physical Activity for Ethnic Minority Women. Psychology \& Health, 14, 277-293. http://dx.doi.org/10.1080/08870449908407328

Deci, E. L., \& Ryan, R. M. (2010). Self-Determination: Wiley Online Library.

Ekkekakis, P. (2009). Let Them Roam Free? Physiological and Psychological Evidence for the Potential of Self-Selected Exercise Intensity in Public Health. Sports Medicine, 39, 857-888. http://dx.doi.org/10.2165/11315210-000000000-00000

Ekkekakis, P., Backhouse, S. H., Gray, C., \& Lind, E. (2008). Walking Is Popular among Adults but Is It Pleasant? A Framework for Clarifying the Link between Walking and Affect as Illustrated in Two Studies. Psychology of Sport and Exercise, 9, 246-264. http://dx.doi.org/10.1016/j.psychsport.2007.04.004

Garber, C. E., Blissmer, B., Deschenes, M. R., Franklin, B., Lamonte, M. J., Lee, I.-M., \& Swain, D. P. (2011). Quantity and Quality of Exercise for Developing and Maintaining Cardiorespiratory, Musculoskeletal, and Neuromotor Fitness in Apparently Healthy Adults: Guidance for Prescribing Exercise. Medicine \& Science in Sports \& Exercise, 43, 1334-1359. 
http://dx.doi.org/10.1249/MSS.0b013e318213fefb

Jekauc, D., Voelkle, M., Wagner, M. O., Mewes, N., \& Woll, A. (2013). Reliability, Validity, and Measurement Invariance of the German Version of the Physical Activity Enjoyment Scale. Journal of Pediatric Psychology, 38, 104-115. http://dx.doi.org/10.1093/jpepsy/jss088

Kahneman, D., Fredrickson, B. L., Schreiber, C. A., \& Redelmeier, D. A. (1993). When More Pain Is Preferred to Less: Adding a Better End. Psychological Science, 4, 401-405. http://dx.doi.org/10.1111/j.1467-9280.1993.tb00589.x

Loewenstein, G. F., Weber, E. U., Hsee, C. K., \& Welch, N. (2001). Risk as Feelings. Psychological Bulletin, 127, $267-286$. http://dx.doi.org/10.1037/0033-2909.127.2.267

McAuley, E., Morris, K. S., Motl, R. W., Hu, L., Konopack, J. F., \& Elavsky, S. (2007). Long-Term Follow-Up of Physical Activity Behavior in Older Adults. Health Psychology, 26, 375-380. http://dx.doi.org/10.1037/0278-6133.26.3.375

Mujika, I., \& Padilla, S. (2000). Detraining: Loss of Training-Induced Physiological and Performance Adaptations. Part I: Short Term Insufficient Training Stimulus. Sports Medicine, 30, 79-87. http://dx.doi.org/10.2165/00007256-200030020-00002

Reiner, M., Niermann, C., Jekauc, D., \& Woll, A. (2013). Long-Term Health Benefits of Physical Activity-A Systematic Review of Longitudinal Studies. BMC Public Health, 13, 813. http://dx.doi.org/10.1186/1471-2458-13-813

Rhodes, R. E., Fiala, B., \& Conner, M. (2009). A Review and Meta-Analysis of Affective Judgments and Physical Activity in Adult Populations. Annals of Behavioral Medicine, 38, 180-204. http://dx.doi.org/10.1007/s12160-009-9147-y

Ryan, R. M., \& Deci, E. L. (2000). Self-Determination Theory and the Facilitation of Intrinsic Motivation, Social Development, and Well-Being. American Psychologist, 55, 68-78. http://dx.doi.org/10.1037/0003-066X.55.1.68

Schneider, M. L., \& Kwan, B. M. (2013). Psychological Need Satisfaction, Intrinsic Motivation and Affective Response to Exercise in Adolescents. Psychology of Sport and Exercise, 14, 776-785. http://dx.doi.org/10.1016/j.psychsport.2013.04.005

Schwarz, N., \& Clore, G. L. (1983). Mood, Misattribution, and Judgments of Well-Being: Informative and Directive Functions of Affective States. Journal of Personality and Social Psychology, 45, 513-523. http://dx.doi.org/10.1037/0022-3514.45.3.513

Slovic, P., Finucane, M. L., Peters, E., \& MacGregor, D. G. (2007). The Affect Heuristic. European Journal of Operational Research, 177, 1333-1352. http://dx.doi.org/10.1016/j.ejor.2005.04.006

Trost, S. G., Owen, N., Bauman, A. E., Sallis, J. F., \& Brown, W. (2002). Correlates of Adults' Participation in Physical Activity: Review and Update. Medicine \& Science in Sports \& Exercise, 34, 1996-2001. http://dx.doi.org/10.1097/00005768-200212000-00020

Tucker, J. M., Welk, G. J., \& Beyler, N. K. (2011). Physical Activity in US Adults: Compliance with the Physical Activity Guidelines for Americans. American Journal of Preventive Medicine, 40, 454-461. http://dx.doi.org/10.1016/j.amepre.2010.12.016

Williams, D. M., \& Raynor, H. A. (2013). Disentangling the Effects of Choice and Intensity on Affective Response to and Preference for Self-Selected-Versus Imposed-Intensity Physical Activity. Psychology of Sport and Exercise, 14, 767-775. http://dx.doi.org/10.1016/j.psychsport.2013.04.001 
Scientific Research Publishing (SCIRP) is one of the largest Open Access journal publishers. It is currently publishing more than 200 open access, online, peer-reviewed journals covering a wide range of academic disciplines. SCIRP serves the worldwide academic communities and contributes to the progress and application of science with its publication.

Other selected journals from SCIRP are listed as below. Submit your manuscript to us via either submit@scirp.org or Online Submission Portal.
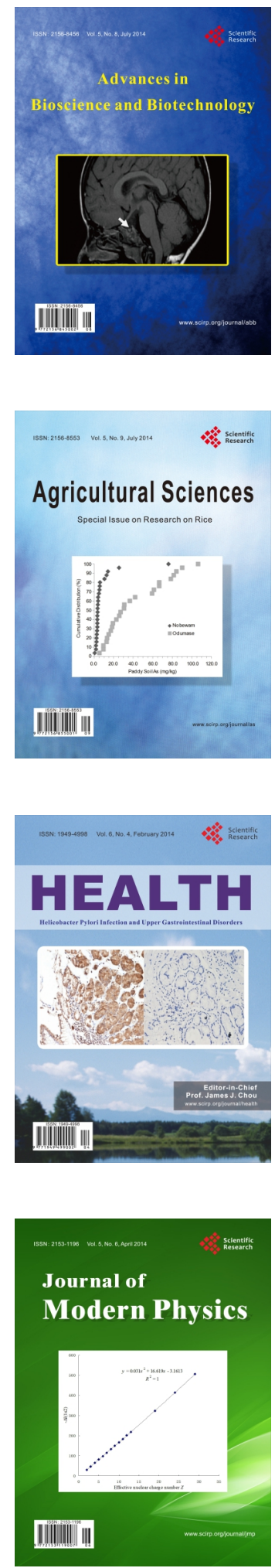
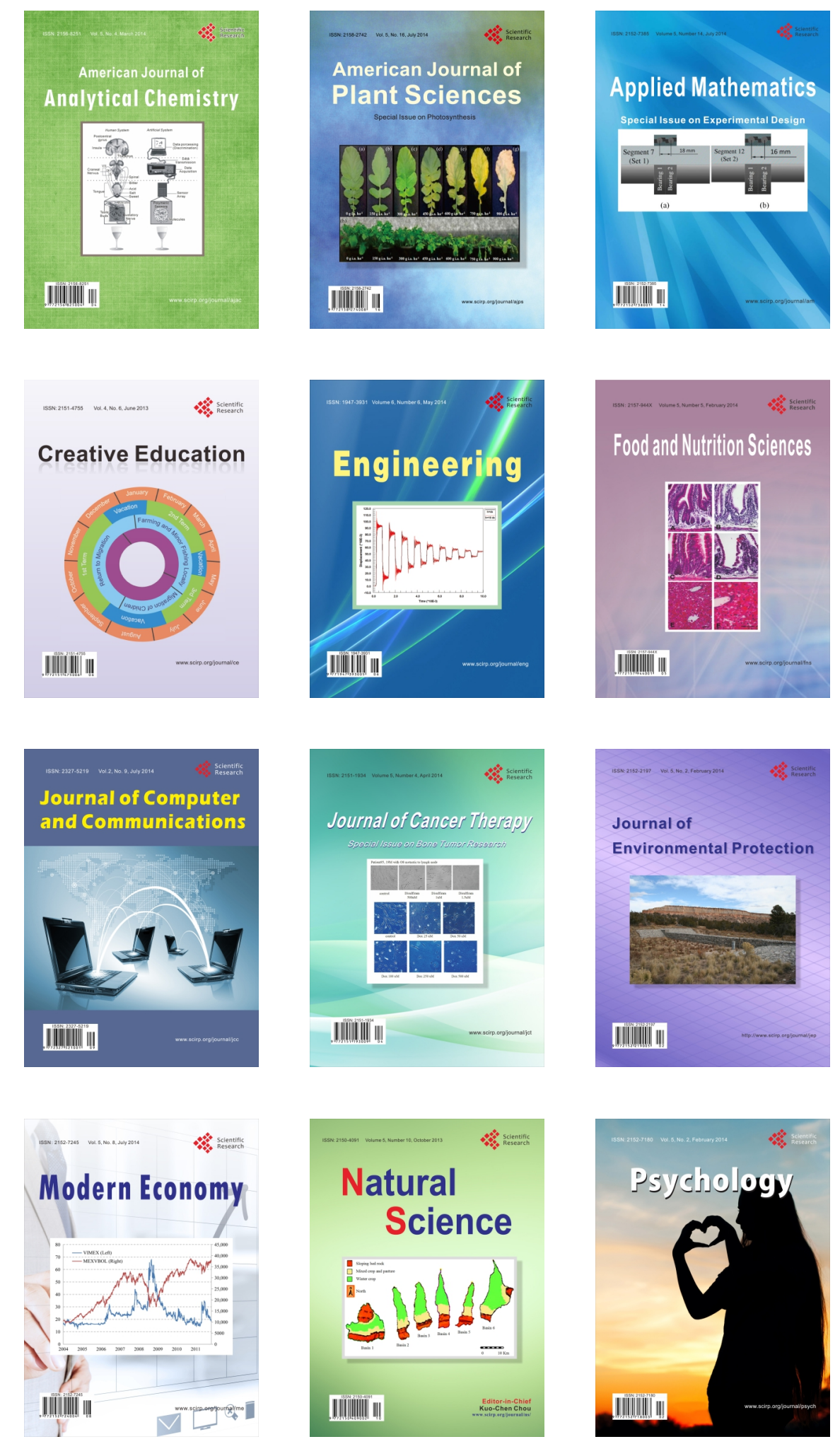